\title{
Economic and Financial Informatics
}

\section{Moawia Alghalith*}

Department of Economics, University of the West Indies, St. Augustine, Trinidad

*Corresponding author: Moawia Alghalith, Department of Economics, University of the West Indies, St. Augustine, Trinidad, Tel: +18686622002; E-mail: malghalith@gmail.com

Received date: Feb 24, 2016; Accepted date: Feb 25, 2016; Published date: Feb 29, 2016

Copyright: (c) 2016 Moawia A. This is an open-access article distributed under the terms of the Creative Commons Attribution License, which permits unrestricted use, distribution, and reproduction in any medium, provided the original author and source are credited.

\section{Editorial}

The interface between informatics and economics is a possibly emerging discipline (economic informatics; see Walters [1] for a discussion). This discipline comprises an overlap between economics / finance, probability / statistics, computer science, and management information systems. Possible areas of applications include risk and uncertainty modeling, asset allocation, options, futures, and swaps, among many others.

Consequently, these developments in informatics will be echoed by developments in probability theory and practice. Examples include stochastic processes, stochastic calculus, probability density estimation, and Monte Carlo simulation, among others.

In this editorial, I will present a brief description of three of my recent papers that may aid in the development of the discipline of economic informatics. Alghalith [2] introduced new non-parametric methods of estimating both the marginal probability density and the joint probability density. In doing so, these methods bypassed the major problem (in existing literature) of bandwidth selection. I applied the methods to stock pricing.
Alghalith [3] presented new parametric methods of estimating both the marginal probability density and the joint probability density. According to the new methods, the probability distribution need not be known a priori. I applied the method to financial data.

Alghalith [4] introduced an EXACT Taylor expansion with CONSTANT coefficients and without the remainder. Moreover, this exact expansion was achieved even if the function is not differentiable. This contribution has many applications in statistics and approximation theory and practice.

\section{References}

1. Walters J (2014) Towards a Discipline of Financial Informatics.

2. Alghalith M (2016a) Novel and simple non-parametric methods of estimating the joint and marginal densities. Physical A: Statistical Mechanics and its Applications, forthcoming.

3. Alghalith M (2015) A New Approach to Density Estimation.

4. Alghalith M (2016b) Exact Taylor Expansions Without Errors for NonDifferentiable Functions. 